DOI: $10.12957 /$ demetra.2016.16168

\title{
Ações de educação alimentar e nutricional para escolares: um relato de experiência
}

\section{Food and nutrition educational action for students: an experience report}

\author{
Bárbara Grassi Prado \\ Emmanuel Nunes Silva Fortes ${ }^{2}$ \\ Maria Aparecida de Lima Lopes ${ }^{3}$ \\ Lenir Vaz Guimarães ${ }^{4}$ \\ 1 Universidade de São Paulo, Faculdade de Saúde \\ Pública. São Paulo-SP, Brasil. \\ ${ }^{2}$ Universidade Federal de Mato Grosso, Curso de \\ Educação Física. Cuiaba-MT, Brasil. \\ ${ }^{3}$ Universidade Federal de Mato Grosso, Faculdade \\ de Nutrição, Departamento de Alimentos e \\ Nutrição. Cuiaba-MT, Brasil. \\ ${ }^{4}$ Universidade Federal de Mato Grosso, Instituto \\ de Saúde Coletiva. Cuiaba-MT, Brasil. \\ Artigo baseado na dissertação de mestrado do \\ Programa de Pós-Graduação em Saúde Coletiva \\ do Instituto de Saúde Coletiva da Universidade \\ Federal de Mato Grosso, defesa em 2011, \\ intitulada Consumo alimentar de escolares \\ antes e após ações de educação nutricional, em \\ Cuiabá-MT.
}

Financiamento: Fundação de Amparo à Pesquisa do Estado de Mato Grosso - FAPEMAT, Processo 469031/2009.

Correspondência / Correspondence Bárbara Grassi Prado

E-mail:prado.barbaragrassi@gmail.com.

\section{Resumo}

Objetivo: O artigo se propõe a descrever uma experiência de ações de educação alimentar e nutricional (EAN) com escolares. Métodos: O relato baseia-se em um estudo de intervenção comunitário desenvolvido com escolares de uma escola pública estadual de Cuiabá, Mato Grosso. A intervenção consistiu em 11 encontros de EAN realizados na escola, com duração de 60 minutos cada. Foram ministradas aulas expositivas e dialogadas, com atividades lúdicas correspondentes ao tema de cada encontro. Para tal, foram utilizados pôsteres, vídeos, jogos e atividades de recorte e colagem como material de apoio pedagógico. Resultados: O tema principal da EAN foi alimentação saudável, com ênfase na redução do consumo de alimentos considerados poucos saudáveis, como doces, refrigerantes e frituras; e incentivo para o consumo de frutas, hortaliças e merenda escolar, em detrimento de lanches poucos saudáveis oferecidos pelas cantinas escolares, vendas perto da escola e trazidos de casa para serem consumidos no ambiente escolar. O uso de jogos e brincadeiras foi bem aceito pelos escolares. Além dos conceitos de nutrição, pôde-se estimular sua autonomia e criatividade. Conclusão: A metodologia empregada neste estudo mostra-se efetiva, uma vez que foi observada a satisfação dos escolares com as atividades ministradas. Recomenda-se que ações de EAN integrem o currículo escolar, sejam planejadas por equipe multiprofissional e sejam adotadas na realização de ações futuras.

Palavras-chave: Educação Alimentar e Nutricional. Consumo Alimentar. Estudantes. Estudos de Intervenção. 


\section{Abstract}

Objective: This article aims to describe a successful experience of food and nutrition education activities (EAN) with school. Methods: This report is based on a randomized community intervention developed with students from a public school in Cuiabá, Mato Grosso state, Brazil. The intervention consisted in 11 meetings on school of nutrition education, with 60 minutes each. Expositive and dialogued classes, and play activities related to the theme of each meeting were given. For this, we used posters, videos, games and activities and clipping collage as teaching support material. Results: The main theme of food and nutrition education actions was healthy eating, emphasizing the reduced consumption of foods considered less healthy like candy, sodas and fries, encouraging increased consumption of fruits and vegetables and consumption of school lunch instead of a few healthy snacks offered by school canteens, sales near school and brought home to be eaten at school. The use of games and play was well accepted by the students. Beyond the concepts of nutrition, we could stimulate their creativity and autonomy. Conclusion: The methodology used in this study shows to be effective, since it was observed satisfaction with school activities taught. It is recommended that food and nutrition education actions integrate the school curriculum, planned by a multidisciplinary team and serve as an aid in planning future actions.

Key words: Food and Nutrition Education. School Feeding. Food Consumption. Students. Intervention Studies.

\section{Introdução}

A Política Nacional de Alimentação e Nutrição possui como diretriz a promoção de práticas alimentares adequadas e saudáveis, compreendendo um conjunto de ações que objetivam proporcionar práticas alimentares nutricionalmente adequadas condizentes com os aspectos biológicos e socioculturais dos indivíduos e coletividades. A Educação Alimentar e Nutricional (EAN) integra estas ações em conjunto com a regulação de alimentos e incentivo à criação de ambientes promotores da alimentação saudável, como os locais de trabalho e as escolas. ${ }^{1}$

Nas escolas, as ações de EAN estão entre os eixos prioritários do Programa Nacional de Alimentação Escolar (PNAE), servindo de auxílio aos escolares na adoção voluntária de escolhas alimentares saudáveis. ${ }^{2,3}$ 
Mediante os problemas alimentares e nutricionais atuais, a EAN se consolida como uma importante estratégia de promoção da saúde. Suas ações baseiam-se em diferentes abordagens educacionais e pedagógicas que propiciam o diálogo e a reflexão sobre aspectos relacionados a alimentação e nutrição ao longo da vida dos indivíduos. ${ }^{4,5}$

Trata-se de um campo intersetorial e multidisciplinar, por isso o nutricionista deve atuar em conjunto com outros profissionais, a fim de elaborar e executar as ações, compartilhando experiências no planejamento das atividades de educação alimentar e nutricional. Na comunidade escolar, diretores, coordenadores, professores, merendeiras, donos e funcionários de cantinas escolares são profissionais que devem ser incentivados a envolver-se nessas ações, para diversificar os métodos educativos e aproximar o saber técnico e popular. ${ }^{5,6}$

Os métodos de ensino-aprendizagem utilizados nas ações de EAN devem diferir de acordo com o ambiente realizado e o público-alvo, e para a escolha dos métodos e temas, torna-se importante realizar uma avaliação diagnóstica por meio de entrevistas ou aplicação de questionários. A utilização de atividades lúdicas, principalmente com escolares, tem-se mostrado efetiva na ampliação do conhecimento sobre alimentos e nutrição, pois estimulam a compreensão do conteúdo abordado de forma prazerosa e refletem a realidade vivenciada em sua faixa etária., ${ }^{7,8}$

Apesar do reconhecimento da importância da EAN, há uma diversidade de abordagens utilizadas, poucos relatos de experiências e, desta forma, a discussão sobre as possibilidades, limites e os métodos utilizados na sua realização ainda é escassa.

O presente artigo se propõe a descrever uma experiência de ações de educação alimentar e nutricional com escolares.

\section{Métodos}

Trata-se da descrição de uma experiência de ações de EAN, desenvolvida em uma escola pública estadual, localizada na área urbana do município de Cuiabá, estado do Mato Grosso. As ações de educação alimentar e nutricional relatadas integram um projeto maior de intervenção, intitulado "Consumo alimentar de escolares antes e após ações de educação nutricional, em Cuiabá-MT". 9 O estudo foi realizado de março a junho de 2010, com 49 escolares de 8 a 14 anos, matriculados no $5^{\underline{o}}$ ano do ensino fundamental.

Para a avaliação diagnóstica da população estudada, as variáveis sociodemográficas analisadas foram sexo, idade e renda mensal per capita (em salários mínimos per capita), classificada segundo o Instituto Brasileiro de Geografia e Estatística. ${ }^{10} \mathrm{O}$ salário-mínimo vigente no país no período da pesquisa era de $\mathrm{R} \$ 510,00$. 
Determinou-se, ainda, o estado nutricional dos escolares por meio do Índice de Massa Corporal (IMC), a partir do peso (kg) e estatura (m) aferidos conforme as recomendações de Jelliffe; ${ }^{11}$ para a classificação do IMC por idade, foram considerados os pontos de corte preconizados pela Organização Mundial da Saúde ${ }^{12}$ e os resultados foram categorizados em com e sem sobrepeso.

Para complementar a avaliação diagnóstica e para o planejamento das ações de educação alimentar e nutricional, aplicou-se um questionário semiestruturado com questões relativas ao consumo de alimentos na merenda escolar, cantina escolar, venda perto da escola e trazidos de casa para o ambiente escolar, resultados que podem ser vistos em Prado et al..$^{13}$ Assim, foi elaborado um projeto de intervenção composto de ações de educação alimentar e nutricional efetivadas em 11 encontros na escola, com duração de 60 minutos cada. As ações foram realizadas por dois pesquisadores denominados "pesquisadora principal" (nutricionista) e "pesquisador auxiliar" (educador físico) que abordaram os temas: pirâmide alimentar, ${ }^{14}$ grupos alimentares com apresentação dos principais nutrientes ${ }^{15} \mathrm{e}$ alimentação saudável. ${ }^{16}$

A cada encontro foram ministradas aulas expositivas e dialogadas de aproximadamente 20 minutos e, posteriormente, foram realizadas atividades lúdicas correspondentes ao tema de cada encontro. Para tal, foram utilizados pôsteres, vídeos, jogos e atividades de recorte e colagem, como material de apoio. Os vídeos foram cuidadosamente selecionados da internet e os pôsteres, jogos e atividades de recorte e colagem foram confeccionados pela pesquisadora principal, com o uso de materiais recicláveis, como garrafa pet e caixas de sapato. No início de cada encontro, buscouse resgatar conceitos anteriormente abordados e surgidos ao longo dos encontros, mediante a interação dos escolares com os pesquisadores.

A pesquisa foi aprovada pelo Comitê de Ética em Pesquisa do Hospital Universitário Júlio Müller da Universidade Federal de Mato Grosso, sob o protocolo no 734/CEP-HUJM/09. Os autores declaram ausência de conflitos de interesse no desenvolvimento desta pesquisa.

\section{Resultados e Discussão}

Apresenta-se no presente artigo um relato de experiência baseado em ações de educação alimentar e nutricional, com escolares de 8 a 14 anos, em uma escola estadual de Cuiabá-MT.

Dados da avaliação diagnóstica mostraram que a população de estudo foi composta por 49 escolares, sendo $58 \%$ do sexo feminino e com idade média de 10,2 anos. Em relação à renda familiar, $58 \%$ das famílias dos escolares tinham renda mensal per capita menor que 0,5 salários mínimos e 42\% apresentavam renda mensal de 0,5 a 2,99 salários mínimos per capita. Quanto ao estado nutricional dos escolares, $13,3 \%$ apresentavam excesso de peso. 
Os resultados do questionário semiestruturado apontaram o alto consumo de alimentos pouco saudáveis, como doces, refrigerantes e frituras, no ambiente escolar, adquiridos em cantinas, vendas perto da escola e trazidos de casa. ${ }^{13}$ Por isso, escolheu-se como tema principal das ações de educação alimentar e nutricional a alimentação saudável, com ênfase na redução do consumo de alimentos considerados poucos saudáveis, como doces, refrigerantes e frituras. Incentivou-se o consumo de frutas, hortaliças e merenda escolar, em detrimento de lanches poucos saudáveis oferecidos pelas cantinas escolares, vendas perto da escola e trazidos de casa para serem consumidos no ambiente escolar.

Os temas, conteúdos programáticos e atividades realizadas em cada encontro das ações de educação alimentar e nutricional estão descritos no quadro 1, em que para cada tema, foram descritas a importância, fonte alimentar e recomendações de cada grupo da pirâmide alimentar, além de atividades lúdicas como recorte e colagem, teatro e jogos.

Quadro 1. Descrição dos temas, conteúdos programáticos e atividades lúdicas trabalhados nos encontros de educação alimentar e nutricional. Cuiabá-MT, 2010.

\begin{tabular}{|c|c|c|}
\hline Temas & Conteúdo Programático & Atividades \\
\hline $\begin{array}{l}\text { Pirâmide } \\
\text { Alimentar }\end{array}$ & $\begin{array}{l}\text { - Importância da pirâmide alimentar; } \\
\text { - Identificação e importância dos grupos } \\
\text { alimentares (carboidratos, óleos e gorduras, } \\
\text { açúcares, hortaliças, frutas, leguminosas, leite e } \\
\text { derivados e carnes e ovos); } \\
\text { - Quantidade de calorias e porções recomendadas } \\
\text { para cada grupo. }\end{array}$ & $\begin{array}{l}\text { - Recorte e } \\
\text { colagem da } \\
\text { pirâmide } \\
\text { alimentar }\end{array}$ \\
\hline $\begin{array}{l}\text { Cereais, } \\
\text { tubérculos, } \\
\text { pães e raízes }\end{array}$ & $\begin{array}{l}\text { - Importância de cereais, tubérculos, pães e raízes; } \\
\text { - Carboidratos e sua importância; } \\
\text { - Fontes alimentares; } \\
\text { - Quantidade de calorias e porções recomendadas } \\
\text { segundo o Guia Alimentar para a População Brasileira. }\end{array}$ & $\begin{array}{l}\text { - Jogo da caça } \\
\text { aos carboidratos }\end{array}$ \\
\hline Hortaliças & $\begin{array}{l}\text { - Importância do grupo alimentar hortaliças; } \\
\text {-Vitaminas e minerais e sua importância; } \\
\text { - Fontes alimentares; } \\
\text { - Quantidade de calorias e porções recomendadas } \\
\text { segundo o Guia Alimentar para a População Brasileira. }\end{array}$ & $\begin{array}{l}\text { - Jogo da } \\
\text { memória das } \\
\text { hortaliças }\end{array}$ \\
\hline
\end{tabular}




\begin{tabular}{|c|c|c|}
\hline Temas & Conteúdo Programático & Atividades \\
\hline Frutas & $\begin{array}{l}\text { - Importância das frutas; } \\
\text { - Vitaminas e minerais e sua importância; } \\
\text { - Fontes alimentares; } \\
\text { - Quantidade de calorias e porções recomendadas } \\
\text { segundo o Guia Alimentar para a População Brasileira. }\end{array}$ & $\begin{array}{l}\text { - Jogo de } \\
\text { dominó das } \\
\text { frutas }\end{array}$ \\
\hline $\begin{array}{l}\text { Leite e } \\
\text { produtos } \\
\text { lácteos }\end{array}$ & $\begin{array}{l}\text { - Importância do leite e produtos lácteos; } \\
\text { - Cálcio e sua importância; } \\
\text { - Fontes alimentares; } \\
\text { - Quantidade de calorias e porções recomendadas } \\
\text { segundo o Guia Alimentar para a População Brasileira. }\end{array}$ & $\begin{array}{l}\text { - Jogo de } \\
\text { boliche dos } \\
\text { leites e produtos } \\
\text { lácteos }\end{array}$ \\
\hline Carnes e ovos & $\begin{array}{l}\text { - Importância de carnes e ovos; } \\
\text { - As proteínas e sua importância; } \\
\text { - Fontes alimentares; } \\
\text { - Quantidade de calorias e porções recomendadas } \\
\text { segundo o Guia Alimentar para a População Brasileira. }\end{array}$ & $\begin{array}{l}\text { - Jogo prato de } \\
\text { carnes }\end{array}$ \\
\hline Leguminosas & $\begin{array}{l}\text { - Importância das leguminosas; } \\
\text { - Ferro e sua importância; } \\
\text { - Fontes alimentares; } \\
\text { - Quantidade de calorias e porções recomendadas } \\
\text { segundo o Guia Alimentar para a População Brasileira; } \\
\text { - Demonstração de } 4 \text { leguminosas (soja, ervilha, } \\
\text { feijão e lentilha). }\end{array}$ & $\begin{array}{l}\text { - Atividade } \\
\text { de colagem } \\
\text { de porções de } \\
\text { leguminosas } \\
\text { secas }\end{array}$ \\
\hline $\begin{array}{l}\text { Óleos e } \\
\text { gorduras }\end{array}$ & $\begin{array}{l}\text { - Importância de óleos e gorduras; } \\
\text { - As gorduras e sua importância; } \\
\text { - Fontes alimentares; } \\
\text { - Quantidade de calorias e porções recomendadas } \\
\text { segundo o Guia Alimentar para a População Brasileira. }\end{array}$ & $\begin{array}{l}\text { - Teatro surpresa } \\
\text { durante a } \\
\text { exposição } \\
\text { dialogada sobre } \\
\text { o consumo de } \\
\text { salgadinhos de } \\
\text { pacote; } \\
\text { - Atividade } \\
\text { de recorte e } \\
\text { colagem dos } \\
\text { alimentos ricos } \\
\text { em óleos e } \\
\text { gorduras }\end{array}$ \\
\hline
\end{tabular}




\begin{tabular}{|c|c|c|}
\hline Temas & Conteúdo Programático & Atividades \\
\hline $\begin{array}{l}\text { Açúcares e } \\
\text { doces }\end{array}$ & $\begin{array}{l}\text { - Importância de açúcares e doces; } \\
\text { - Fontes alimentares; } \\
\text { - Quantidade de calorias e porções recomendadas } \\
\text { segundo o Guia Alimentar para a População Brasileira. }\end{array}$ & $\begin{array}{l}\text { - Jogo da } \\
\text { criança saudável }\end{array}$ \\
\hline $\begin{array}{l}\text { Alimentação } \\
\text { saudável }\end{array}$ & $\begin{array}{l}\text { - Leis da alimentação; } \\
\text { - Como montar uma refeição saudável através da } \\
\text { escolha de alimentos saudáveis; } \\
\text { - Importância de cada refeição; } \\
\text { - Sugestões de cardápio ideal para cada tipo de } \\
\text { refeição; } \\
\text { - Importância do café da manhã. }\end{array}$ & $\begin{array}{l}\text { - Jogo da } \\
\text { alimentação } \\
\text { saudável }\end{array}$ \\
\hline $\begin{array}{l}\text { Vídeos sobre } \\
\text { Alimentação } \\
\text { saudável }\end{array}$ & $\begin{array}{l}\text { Vídeo de aproximadamente } 25 \text { minutos sobre os } \\
\text { temas: } \\
\text { - O café da manhã; } \\
\text { - O leite e seus derivados; } \\
\text { - Como se faz o pão; } \\
\text { - As frutas; } \\
\text { - Conservando a água; } \\
\text { - De onde vem o sal? } \\
\text { - De onde vem o ovo? } \\
\text { - Conhecendo os alimentos; } \\
\text { - Obesidade infantil. }\end{array}$ & $\begin{array}{l}\text { - Vídeos sobre } \\
\text { alimentação } \\
\text { saudável }\end{array}$ \\
\hline
\end{tabular}

Para integrar a equipe de pesquisadores, além da nutricionista, optou-se por um profissional de Educação Física, pois se reconhece sua habilidade na prática de atividades em grupo e a importância da multidisciplinaridade na realização deste tipo de intervenção, constatadas durante a execução dos encontros.

Com o intuito de tornar as atividades prazerosas tanto para o educador quanto para o educando, procurou-se estabelecer um vínculo afetivo entre eles durante as ações de educação nutricional, pois de acordo com Freire, ${ }^{17}$ a competência técnica e a amorosidade são relações educativas imprescindíveis ao sucesso do aprendizado.

O vínculo afetivo permitiu direcionar os conteúdos das ações para a realidade dos escolares, abordando-se as questões nutricionais desveladas na aplicação do questionário semiestruturado. Desta forma, nas ações de EAN, adotaram-se estratégias metodológicas inerentes à faixa etária estudada, como aulas expositivas, dialogadas e atividades lúdicas. 
No primeiro encontro, sobre o tema "pirâmide alimentar", os pesquisadores se apresentaram em voz alta e cada escolar foi identificado com um crachá em formato de laranja. Optou-se por trabalhar a Pirâmide Alimentar Adaptada para a População Brasileira, ${ }^{14}$ uma vez que os guias alimentares servem como instrumentos de orientação e informação à população, objetivando a promoção da saúde e adoção de hábitos alimentares saudáveis. Yokota et al. ${ }^{18}$ também utilizaram a pirâmide alimentar como instrumento para a educação alimentar e nutricional com escolares e professores, e obtiveram resultados positivos da intervenção.

Philippi et al. ${ }^{14}$ ressaltam a importância de se trabalhar cada grupo alimentar, destacando sua importância, fontes alimentares e recomendações, para que o objetivo principal seja alcançado, ou seja, a adoção de uma alimentação saudável. Desta forma, cada grupo alimentar foi trabalhado separadamente, incluindo-se, ao final de cada encontro, uma atividade lúdica, com jogos existentes e adaptados aos conceitos de uma alimentação saudável. A escolha de jogos pauta-se na perspectiva que, para o ser humano, a aprendizagem é tão importante quanto o desenvolvimento social, sendo o jogo uma ferramenta pedagógica que promove tanto o desenvolvimento cognitivo quanto o social. O jogo pedagógico deve promover alegria, prazer, diversão, e assim, a aprendizagem, ${ }^{19} \mathrm{o}$ que foi observado durante todo o processo educativo.

No encontro sobre o grupo alimentar "Cereais, Tubérculos, Pães e Raízes", ministrou-se a atividade "jogo da caça aos carboidratos", cuja principal função dos carboidratos, que consiste em gerar energia ao organismo, foi demonstrada por meio da energia dispendida para "correr" em busca das figuras de alimentos. Os escolares foram estimulados a identificar os erros e assim, fixar o conteúdo abordado.

Durante o encontro sobre as hortaliças, observou-se que muitos escolares desconheciam algumas delas, como acelga, rúcula, nabo, abobrinha, entre outras. As hortaliças mais citadas foram cenoura, tomate, alface e repolho, o que condiz com os alimentos mais consumidos pela população brasileira. ${ }^{20}$ Por isso, solicitou-se aos escolares que fossem ao mercado com seus pais/ responsáveis para conhecerem melhor as hortaliças citadas em sala de aula. O “jogo da memória das hortaliças" estimulou a curiosidade na identificação de cada hortaliça ilustrada nas peças do jogo.

No encontro sobre frutas, alguns escolares reportaram a experiência da ida ao mercado para identificar as hortaliças apresentadas na aula anterior. Segundo Freire, ${ }^{21}$ situações concretas da realidade auxiliam na construção de um conhecimento baseado na sua vivência e possibilidades, excluindo-se o ensino baseado em diálogo singular e vertical entre o educador e o educando, em que a realidade se torna algo estático e distante de sua realidade e experiências individuais. Por meio do processo de avaliação formativa, notou-se que a atividade proposta alcançou o objetivo de despertar curiosidade e construção do conhecimento que perfazem o aprendizado em sala de aula.

Além das frutas mais consumidas, os escolares citaram as frutas e preparações regionais, como a bocaiuva, pequi e a farofa de banana, que é uma preparação regional à base de banana da terra. 
Assim, como forma de valorizar atividades que respeitam e perpetuam a tradição e história cultural e alimentar dos indivíduos, ${ }^{22}$ incentivou-se o consumo de frutas colhidas no próprio quintal, prática comum no município de Cuiabá-MT e região. A valorização da cultura local também foi realizada por $\operatorname{Boog}^{23}$ em seu estudo de intervenção com uma comunidade escolar rural, em que incentivou o consumo de alimentos produzidos na região, gerando grande interesse dos alunos, pois as atividades refletiam seu próprio cotidiano e valorizavam o trabalho, a história, a identidade cultural e a autoestima das famílias.

Durante o encontro sobre leite e produtos lácteos, os escolares relataram baixo consumo desse grupo, que era substituído pelo consumo de chás e café. Gambardella et al. ${ }^{24}$ encontraram relação entre baixo consumo de leite e derivados e a omissão do desjejum, pois estes alimentos geralmente compõem essa refeição. No presente estudo, os escolares também relataram baixa frequência de desjejum, o que pode explicar o baixo consumo de leite e produtos lácteos.

No encontro sobre carnes e ovos, abordou-se sobre o consumo e modo de preparo destes alimentos (assados, cozidos, refogados, grelhados e frituras). Observou-se que os escolares reportavam o consumo frequente de preparações regionais como galinha com arroz e "maria isabel" (arroz com carne seca), além do consumo excessivo de embutidos, como linguiça e salsicha.

Durante o encontro sobre as leguminosas, notou-se o desconhecimento sobre soja, lentilha, ervilha seca e diferentes tipos de feijão como o fradinho, rajado, dentre outros. A maioria conhecia somente a ervilha enlatada, feijão carioca e feijão preto. Ainda, foi realizada a análise sensorial das leguminosas por meio do tato e olfato, pois esta técnica permite o reconhecimento do alimento, aumentando a decisão positiva na experimentação de novos alimentos, ${ }^{25}$ atitude observada nos escolares, mediante o pedido de porções dos alimentos para que pudessem experimentá-los em casa.

O encontro sobre os óleos e gorduras foi iniciado com uma encenação improvisada sobre o consumo de doces e salgadinhos de pacote. O pesquisador auxiliar adentrou a sala, cumprimentou os escolares, abriu um pacote de salgadinho e doces e começou a comê-los. Neste momento os escolares se agitaram, dizendo que ele não podia comer salgadinho, pois fazia mal à saúde. Assim, iniciou-se uma discussão sobre o consumo de salgadinhos industrializados e doces.

A literatura mostra que o uso da dramatização como instrumento de educação permite a interação entre o educador e o educando, e sua utilização pode favorecer o acesso aos níveis afetivos e emocionais do educando, uma vez utilizada a linguagem adequada ao público-alvo e possibilitada a participação dos educandos. ${ }^{26,27}$ Experiências consideradas positivas foram relatadas por Toassa et al., ${ }^{28}$ que utilizaram a dramatização e dinâmicas de grupo com escolares no intuito de abordar temas de nutrição e qualidade de vida, e por Souza \& Boas, ${ }^{29}$ que utilizaram o teatro de fantoche com crianças e adolescentes para abordarem a importância da vitamina A. No presente estudo, notou-se o interesse dos escolares na participação da dramatização, demonstrando o conhecimento dos malefícios destes alimentos à saúde. 
No encontro sobre açúcares e doces, aplicou-se um jogo com o objetivo de extrair das caixas as figuras de alimentos (açúcares e doces) que, em excesso, podem ocasionar diversas doenças. Notou-se que houve participação ativa dos escolares e o entendimento da atividade.

No encontro sobre o tema "alimentação saudável", o tema "café da manhã” foi o mais discutido pelos alunos, pois muitos relatavam jejum matinal, sendo a primeira refeição do dia constituída pela merenda escolar, ou seja, duas a três horas após acordarem. A literatura mostra que esta prática é comum entre crianças e adolescentes e que está associada à obesidade. ${ }^{29,30}$ Assim, os escolares foram sensibilizados a iniciarem esta prática, introduzindo, no mínimo, um alimento considerado saudável, como pão, fruta, leite, biscoito de sal, entre outros.

O jogo da "alimentação saudável" foi um sucesso e os escolares jogaram diversas rodadas. Os cartões com o tema sobre alimentação saudável auxiliaram na assimilação dos conteúdos de todas as aulas anteriores.

No último encontro, ainda sobre o tema "alimentação saudável”, foram utilizados vídeos como estratégia metodológica, que, por sua vez, apreenderam a atenção dos escolares, que pediram para repetir diversas vezes, imitando as falas dos personagens. Os vídeos continham personagens em formato de alimentos, músicas e curiosidades sobre o caminho percorrido pelos alimentos até a mesa dos personagens.

Os vídeos foram selecionados criteriosamente da internet, evitando-se a utilização de conceitos errôneos. Desta forma, foi possível observar a disponibilidade de vídeos com qualidade de informações sobre o tema nutrição. Boog et al. ${ }^{27}$ utilizaram um vídeo com o intuito de problematizar o tema "obesidade" e relataram experiência positiva no uso deste tipo de instrumento, como no presente estudo.

Assim, os jogos e brincadeiras foram bem aceitos pelos escolares. Além dos conceitos de nutrição, pôde-se estimular sua autonomia e criatividade. Apesar de as atividades terem sido previamente planejadas, os pesquisadores encontravam-se abertos às sugestões dos escolares na condução da aula e das atividades lúdicas, pois é necessário que o educador reconheça a importância da descentralização do papel do professor, proporcionando autonomia ao educando, o que estimula a espontaneidade e criatividade no enfrentamento do inesperado. ${ }^{31,32}$

Os jogos foram confeccionados pelos pesquisadores, com materiais, em sua maioria, recicláveis e de fácil replicação pelos alunos. Entretanto, reconhece-se que a confecção dos mesmos pelos próprios escolares poderia favorecer a maior interação destes com o tema proposto. Isto não foi possível, pela necessidade de maior tempo de realização do projeto e de integração com outras disciplinas curriculares. 
Por meio de uma avaliação formativa, foram observados grande participação e interesse dos escolares com os temas e as estratégias utilizadas nas ações de EAN. Considera-se que a atividade proposta cumpriu seu objetivo, de proporcionar conhecimento sobre alimentação saudável, sensibilizando-os na adoção de hábitos alimentares saudáveis. Ressalta-se que a adoção permanente de hábitos alimentares saudáveis é uma missão complexa e desafiadora, em que há a necessidade de um processo de ensino permanente e contínuo. Deminice et al. ${ }^{33}$ realizaram um estudo de intervenção com escolares de Ribeirão Preto-SP e observaram aumento no nível de conhecimento sobre alimentação saudável, concluindo que ações de curta duração não ocasionam efeito significativo no estado nutricional e consumo alimentar dos escolares, necessitando de ações de longa duração.

Ações com pequenas durações, como do presente estudo, já surtem efeitos positivos na alimentação dos escolares, que foram observadas por meio da comparação do efeito positivo da intervenção antes e após sua realização, utilizando um questionário sobre o consumo da merenda escolar, alimentos oferecidos pela cantina escolar, vendas perto da escola e trazidos de casa. Assim, foram observados aumento no consumo semanal de alimentos trazidos de casa para o ambiente escolar, aumento da preferência por frutas e salada de frutas oferecidas pela merenda escolar e redução na aquisição de balas, pirulitos e chicletes na cantina escolar. Estes resultados são apresentados e discutidos no artigo de Prado et al. ${ }^{13}$

\section{Conclusão}

Os resultados deste estudo são considerados favoráveis, uma vez que a avaliação formativa aponta para o entendimento, interesse, participação e relatos positivos dos escolares das atividades propostas. Entretanto, acredita-se que essas atividades compõem um pequeno início no aprendizado sobre alimentação saudável, pois ações efetivas e duradouras devem ser realizadas de forma contínua e permanente, desde a primeira infância.

Vale ressaltar que as atividades relatadas integram algumas estratégias que podem ser aplicadas no ambiente escolar. E ainda, podem-se ampliar os temas escolhidos e incluir outros métodos de ensino, como oficinas culinárias, cultivo de horta escolar, paródias, entre outros.

Acreditando-se que o ambiente escolar é um lugar propício para atividades de educação alimentar e nutricional, por conter um grupo exposto cotidianamente ao aprendizado, recomenda-se que essas ações integrem o currículo escolar e sejam planejadas por uma equipe multiprofissional, incluindo o nutricionista. Para tal, há a necessidade de capacitar professores, merendeiras, dirigentes escolares, donos de cantinas e de outros profissionais da escola, a fim de ampliar a realização dessas atividades, pois conversas informais e atitudes simples também constituem estratégias de educação alimentar e nutricional. 
Espera-se, assim, que o presente relato de experiência amplie a discussão sobre as estratégias adotadas em ações de educação alimentar e nutricional com escolares e a realização de ações futuras.

\section{Agradecimentos}

À Fundação de Amparo à Pesquisa do Estado de Mato Grosso (FAPEMAT) e à Coordenação de Aperfeiçoamento de Pessoal de Nível Superior (CAPES), pelo apoio financeiro.

\section{Referências}

1. Brasil. Ministério da saúde. Política nacional de alimentação e nutrição. Brasília: Ministério da Saúde; 2012.

2. Brasil. Portaria Interministerial no 1.010 , de 08 de maio de 2006. Institui as diretrizes para a promoção da alimentação saudável nas escolas de educação infantil, fundamental e nível médio das redes públicas e privas, em âmbito nacional. Diário Oficial da União 09 maio 2006.

3. Brasil. Ministério da saúde. Experiências municipais e estaduais de regulamentação da comercialização de alimentos em escolas no Brasil: relatório técnico. Brasília: Ministério da Saúde; 2007. 73 p.

4. Santos LAS. Educação alimentar e nutricional no contexto promoção de praticas alimentares saudáveis. Rev. Nutr. 2005; 18:681-92.

5. Brasil. Ministério do Desenvolvimento Social e Combate à Fome. Marco de referência de educação alimentar e nutricional para as políticas públicas. Brasília: MDS; 2012.

6. Ferreira VA, Magalhães R. Nutrição e promoção da saúde: perspectivas Atuais. Cad. Saúde Pública 2007; 23:1674-81.

7. Contento, I. Nutrition education: linking research, theory, and practice. Subdury, MA: Jones and Bartlett Publisher; 2007.

8. Coscrato G, Pina JC, Mello DF. Utilização de atividades lúdicas na educação em saúde: uma revisão integrativa da literatura. Acta Paul. Enferm. 2010; 23(2):257-63.

9. Prado BG. Consumo alimentar de escolares antes e após ações de educação nutricional, em CuiabáMT [dissertação]. Cuiabá: Universidade Federal de Mato Grosso; 2011.

10. Instituto Brasileiro de Geografia e Estatística. Pesquisa de orçamentos familiares 2002-2003: análise da disponibilidade domiciliar de alimentos e de estado nutricional no Brasil. Relatório Final. Rio de Janeiro: IBGE; 2004.

11. Jelliffe DB. Evaluación del estado de nutrición de la comunidad. Ginebra: Organización Mundial de la Salud; 1968. 
12. World Health Organization. Development of a WHO growth reference for school-aged children and adolescents. Geneva: WHO; 2007.

13. Prado BG, Guimarães LV, Lopes MAL, Bergamaschi D. Efeito de ações educativas no consumo de alimentos no ambiente escolar. Nutrire 2012; 37(3):281-292.

14. Philippi ST, Latterza AR, Cruz ATR, Ribeiro LC. Pirâmide alimentar adaptada: guia para escolha dos alimentos. Rev. Nutr. 1999; 12:65-80.

15. Brasil. Ministério da saúde. Guia alimentar para a população brasileira: promovendo a alimentação saudável: normas e manuais técnicos. Brasília: Ministério da Saúde; 2008. 210 p.

16. Barioni AAR, Branco MF, Soares VC. Preceitos fundamentais para plano alimentar: finalidades e leis. In: Galisa MS, Esperança LMB, Sá NG. Nutrição: conceitos e aplicações. São Paulo: M. Books do Brasil; 2008. p. 95-100.

17. Freire P. Pedagogia da autonomia: saberes necessários à prática educativa. 23 ed. São Paulo: Paz e Terra; 1996. 148 p.

18. Yokota RTC, Vasconcelos TF, Pinheiro ARO, Schmitz BAS, Coitinho DC. Projeto "a escola promovendo hábitos alimentares saudáveis": comparação de duas estratégias de educação nutricional no Distrito Federal, Brasil. Rev. Nutr. 2010; 23(1):37-47.

19. Delval J. Crescer e pensar: a construção do conhecimento na escola. 2 ed. Porto Alegre: Artmed; 2002.

20. Instituto Brasileiro de Geografia e Estatística. Pesquisa de orçamentos familiares 2008-2009: despesas, rendimentos e condições de vida. Rio de Janeiro: IBGE; 2010.

21. Freire P. Pedagogia da autonomia: saberes necessários à prática educativa. 28 ed. São Paulo: Paz e Terra; 2003. Coleção Leitura.

22. Zuin LFS, Zuin PB. Alimentação é cultura: aspectos históricos e culturais que envolvem a alimentação e o ato de se alimentar. Nutrire 2009; 34(1):225-241.

23. Boog MCF. Programa de educação nutricional em escola de ensino fundamental de zona rural. Rev. Nutr. 2010; 23(6):1005-1017.

24. Gambardella AMD, Frutuoso MFP, Franch C. Prática alimentar de adolescentes. Rev. Nutr. 1999; 12(1):55-63.

25. Duran L, Costell E. Perception of taste. Physiochemical and psychophysical aspects. Food Sci. Tech. Int. 1999; 5(4):299-09.

26. Alves MA. O teatro como um sistema de comunicação. Trans/Form/Ação. 2001; 24(1):85-90.

27. Boog MCF, Vieira CM, Oliveira NL, Fonseca O, L’Abbate S. Utilização de vídeo como estratégia de educação nutricional para adolescentes: comer... o fruto ou o produto? Rev. Nutr. 2003; 16(3):281-293.

28. Toassa EC, Leal GVS, Wen CL, Philippi ST. Atividades lúdicas na orientação nutricional de adolescentes do Projeto Jovem Doutor. Nutrire 2010; 35(3):17-27.

29. Souza WA, Boas OMGCV. Orientação sobre uso de vitamina A na saúde escolar: comparação de técnicas pedagógicas. Ciênc. Saúde Coletiva 2004; 9(1):83-90. 
30. Enns CW, Mickle SJ, Goldman JD. Trends in food and nutrient intakes by adolescents in the United States. Fam. Econ. Nutr. Rev. 2003; 15(2):15-27.

31. Giugliano R, Carneiro EC. Fatores associados à obesidade em escolares. J Pediatr. 2004; 80(1):17-22.

32. Fortuna TR. Aventuras psicopedagógicas na sala de aula: a contribuição do construtivismo piagetiano. Revista Psicopedagogia 1994; 13(31):19-24.

33. Deminice R, Laus MF, Marins M, Silveira SDO, Dutra de Oliveira E. Impacto de um programa de educação alimentar sobre conhecimentos, práticas alimentares e estado nutricional de escolares. Alim. Nutr. 2007; 18(1):35-40.

Recebido: $24 / 4 / 2015$

Revisado: $12 / 10 / 2015$

Aceito: $12 / 1 / 2016$ 